\title{
Load torque analysis and compensation device design for low power drilling fluid continuous wave generator
}

\author{
Jiafeng Wu ${ }^{1} \odot \cdot$ Jianming Jiang ${ }^{1} \cdot$ Botao Zhou $^{1} \cdot$ Shuxing Zhao ${ }^{1} \cdot$ Ning Han $^{1} \cdot$ Dongli Qin $^{2} \cdot$ Ruihe Wang $^{1}$
}

Received: 17 October 2020 / Accepted: 16 April 2021 / Published online: 27 April 2021

(c) The Author(s) 2021

\begin{abstract}
As an advanced downhole instrument in drilling engineering, drilling fluid continuous wave generator (DFCWG) has great application prospects. The large load torque is one of the key problems that hinder the development of DFCWG. In this paper, based on the design theory of rotary valve and finite element method, the structure of rotary valve is designed and the load torque characteristics is analyzed and points out that the load torque has strong alternating characteristics. It is pointed out that the load torque has the characteristics of strong alternating. According to the characteristics of the load torque, the "fluid-magnetic" collaborative compensation method is proposed. The load compensation turbine and magnetic compensation device are used to compensate the DC and AC components of the load torque respectively, and the load compensation device is designed. The rationality of the design of the load compensation device is verified by simulation. Finally, the comprehensive compensation effect is analyzed by the finite element method. According to the analysis results, the "fluidmagnetic" collaborative compensation method can effectively reduce the load torque. The research results can provide technical support for DFCWG design.
\end{abstract}

Keywords Load torque characteristics - "Fluid-magnetic" collaborative compensation method - Load compensation turbine $\cdot$ Magnetic compensation device

\section{Introduction}

In recent years, drilling technology has entered the stage of automated drilling characterized by informatization and intelligence (Klotz et al. 2008). It is necessary to obtain as much underground information as possible in real time, making underground information transmission technology the key to achieving automated drilling. As an advanced underground information transmission technology, the drilling fluid continuous wave technology has a very broad application prospect (Wu et al. 2019).

The key component in producing a drilling fluid continuous wave is the drilling fluid continuous wave generator (DFCWG). It consists of the rotary valve, the rotation system and the driven motor. The rotary valve has a pair of rotor

Jiafeng Wu

wujiafeng@upc.edu.cn

1 School of Petroleum Engineering, China University of Petroleum, Qingdao 266580, China

2 College of Mechanical and Electronic Engineering, China University of Petroleum, Qingdao 266580, China and stator. When DFCWG works, the driven motor drives the rotor to rotate, which periodically changes the flow area formed by the rotor and stator. The pressure disturbance is then generated at the upstream of the rotary valve. The pressure disturbance is called the drilling fluid continuous wave, and it is often used to carry the downhole information.

In the downhole environment, the load torque acting on the continuous wave generator is large due to the influence of the drilling fluid characterized by high speed and high pressure (Jia 2010), and many scholars have studied the characteristics of the load torque. Zhidan Yan et al. (Yan et al. 2018) designed the rotary valve and analyzed the torque acting on the rotary valve via CFD. Jia and Zhan et al. (Jia et al. 2010; Zhan 2012) used three-dimensional flow field simulation to analyze the hydraulic torque of the rotary valve, and the results showed that the hydraulic torque was in an alternating state.

Since the motor is the power source of the DFCWG, the large load torque increases the driven difficulty and power consumption. Therefore, it is important to assist the driving of the motor. Some scholars have tried to assist the motor by adding additional structures. Eric Lavrut et al.

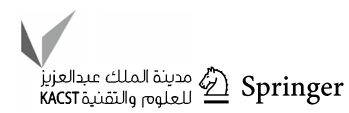


(Eric Lavrut et al., US 6,970,398 B2) proposed adding a turbine to the rear end of the rotary valve, and using the hydraulic characteristics of that turbine to provide additional torque to the motor to help the motor rotate. Detlef Hahn et al. (2005) proposed the design of an oscillating shear valve to reduce the load torque. Namuq et al. (Namuq et al. 2013) proposed an improved structure based on the fan-shaped valve port form. Based on this structure, the motor control method was optimized to reduce the influence of load torque. Shi Rong (Rong et al. 2011) proposed a split-type rotary valve. The rotary valve has the characteristics of simple structure, low power consumption, an unchanging signal transmission rate with the displacement of the mud and a large pressure wave amplitude.

In summary, due to the relative motion of the components in DFCWG, the load torque should include the hydraulic torque acting on the rotary valve and the system friction torque. But the system friction torque has been neglected in previous research. Therefore, the load torque characteristics should be analyzed and the method can be improved to assist the driven motor. Thus, in this paper, the load torque is first analyzed via simulation. The fluid-magnetic cooperative compensation method is then proposed, and the load compensation devices are designed. Finally, the proposed method and devices are tested by simulation. The structure of the paper is as follows: the load torque is analyzed in the second section, the fluid-magnetic cooperative compensation method is clarified in the third section, and finally the rationality of the design is verified. The main contributions of this paper are as follows:

(1) The characteristics of load torque are analyzed by Fourier transform, and the characteristics of DC and AC component are pointed out.

(2) "Fluid-magnetic" cooperative compensation method is proposed to compensate the load torque.

\section{Theory}

\section{The structure of the rotary valve}

In this section, the rotary valve with a known orifice curve is designed to produce the drilling fluid continuous wave. On the assumption that constant pressure generated at the outlet of the rotary valve and the influence of the axial clearance and the radial clearance considered, the rotary valve is designed and studied (Wu 2017). When the rotary valve rotates at a constant speed, the DFCW can be generated at the inlet of the rotary valve. The valve opening can be expressed as (Wu 2017): $\tau(t)=\left[1+4 C C_{d}^{2} A_{o}^{2} \cos ^{2} \frac{N \omega t}{2} /\left(\rho Q^{2}\right)\right]^{-\frac{1}{2}}$

where $C$ is the amplitude of drilling fluid continuous wave; $C_{d}$ is the flow coefficient in rotary valve; $A_{0}$ is the maximum flow area of the rotary valve orifice; $N$ is the number of blades of the rotary valve; $\omega$ is the rotation speed of rotary valve; $t$ is time; $\rho$ is the drilling fluid density; $Q$ is the pump flow.

The orifice curves can be defined in the polar coordinate system. $r(\theta)$ is the polar radius of the valve orifices and denotes the distance from the axial line to the intersection point between the orifice curves of the stator and the rotor where $\theta \in\left[0 \frac{\pi}{N}\right]$. And it can be expressed as (Wu 2017):

$r(\theta)=-\zeta \lambda s+\sqrt{(\zeta \lambda s)^{2}+R^{2}-\frac{k A_{o} \sin (N \theta)}{[k \cos (N \theta)+k+1]^{1.5}}}$

where $\zeta=1-\int_{0}^{1} r\left[\left(\frac{\pi}{N}-\theta\right) x+\theta\right] / r(\theta) d x$ is a correction coefficient that can be used to correct for the influence of the axial clearances on the whole flow area; $k=\frac{C}{P_{o}}=\frac{2 C C_{d}^{2} A_{o}^{2}}{\rho Q^{2}}$ is the relative intensity, $R$ is the outer diameter of the rotor; $s$ is the axial clearance between the stator and rotor, $\theta$ is the rotation angle of the rotor and $r$ is the polar radius. $\lambda$ is the coefficient.

The length $L$ of the orifice curves can be obtained as (Wu 2017):

$L=\int_{0}^{\frac{\pi}{N}} r(\theta) d \theta$

According to the method, the structure of the rotary valve can be determined, and then, the load torque can be calculated based on the structure.

\section{Time domain characteristics of the load torque}

The Fourier analysis method is widely used to analyze signal components. According to this method, any periodic signal can be expressed as a weighted sum of sinusoidal signals in harmonic relationship. Therefore, the load torque can be decomposed into an infinite number of complex exponential harmonic components:

$p(t)=\sum_{k=-\infty}^{\infty} a_{k} e^{j\left(2 \pi k f_{0} t+\theta_{k}\right)}$

where $k$ is the harmonic number, $0, \pm 1, \pm 2 ; a_{k}$ is the harmonic amplitude; $f_{0}$ is fundamental frequency; $\theta_{k}$ is the harmonic initial phase; $t$ is the time.

According to the Fourier transform, the load torque can be divided into the DC component and the alternative 
component, and the load torque compensation method will be proposed based on the load torque characteristics.

\section{Load torque characteristics of DFCWG}

\section{Structure of rotary valve of DFCWG}

Based on the designed method, a rotary valve was designed as shown in Fig. 1, and the dimensions of each part are shown in Table 1 . The rotary valve model includes a rotor and a stator of the same shape with an axial clearance of $2 \mathrm{~mm}$ between the rotor and stator. At the same time, in order to facilitate the analysis of the hydraulic torque acting on the rotary valve, the rotating shaft, the upstream flow path and the downstream flow path are added to the rotary valve model.

\section{Simulation analysis for the load torque}

In this section, the 3D model of the rotary valve is established using SolidWorks software. The mesh model of the rotary valve is established using the Mesh module in ANSYS/CFX. As shown in Fig. 2, the mesh model adopts a hexahedral mesh. When the valve port is fully open, the initial rotation angle of the rotor is $0^{\circ}$, the hydraulic torque acting on the rotor wall surface is observed. The density of the drilling fluid is set to $997 \mathrm{~kg} / \mathrm{m}^{3}$, and the dynamic viscosity is about $8.9 \times 10^{-4} \mathrm{~Pa}$ s. In drilling process, the velocity of drilling fluid in the rotary valve area is relatively high,

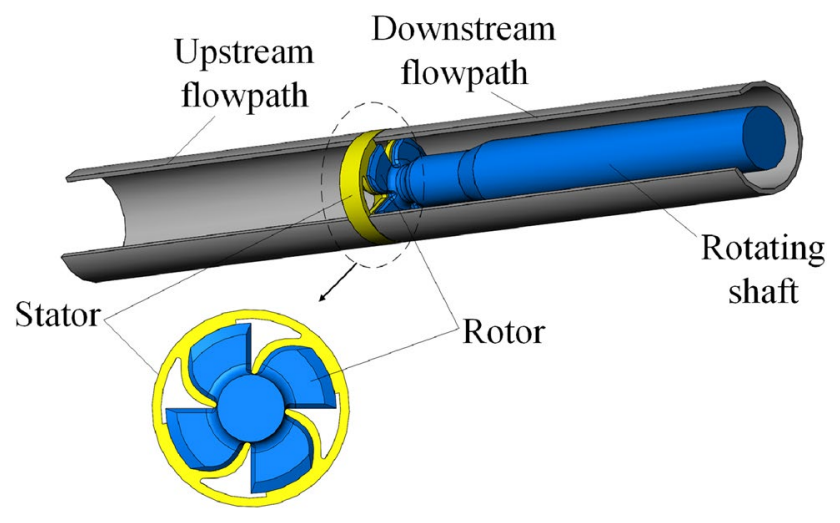

Fig. 1 Rotary valve model for low power continuous wave generator

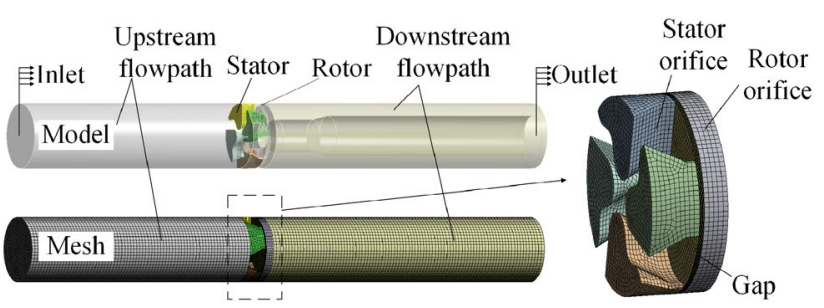

Fig. 2 Mesh model and boundary condition setting

and the flow state of drilling fluid is usually turbulent. The drilling fluid is usually water-based, so it can be considered that the drilling fluid is incompressible. DFCWG is installed in the drill pipe and almost all drilling fluid passes through DFCWG. At the same time, the surface roughness of the inner wall of the drill pipe is low. Therefore, the leakage of drilling fluid and the roughness of the inner wall of the drill pipe can be ignored in the simulation. Because the length of continuous wave generator is short, it can be considered as constant liquid properties and thermal equilibrium conditions in DFCWG area. Thus, the assumptions are made in the simulation: transient conditions, incompressible liquids, neglect of leakage and channel wall roughness, constant liquid properties and thermal equilibrium conditions.

Due to the flow rate through the rotary valve area being large and the flow being turbulent, the $k-\varepsilon$ model is selected for analysis to ensure sufficient calculation accuracy and calculation requirements. The outlet type is set to a constant pressure outlet, and the relative pressure is set to $1.6 \mathrm{MPa}$. To analyze the hydraulic torque at different flow rates, the inlet type is set to the speed inlet, all the walls are set to have no slip boundary and the standard wall equation is used in the near wall area. The flow field at the rotary valve is set to a rotational range of $4 \mathrm{r} / \mathrm{s}$ to generate a $16 \mathrm{~Hz}$ sine wave signal. A second-order backward Euler format is used as the solution method. For the scaling residuals of all parameters, the absolute standard of convergence is set to $10^{-4}$.

\section{Analysis of load torque characteristics}

The load torque acting on DFCWG consists of the hydraulic torque acting on the rotary valve and the system friction torque. The hydraulic torque can be expressed by the

Table 1 Size of rotary valve model for drilling fluid continuous wave generator

\begin{tabular}{|c|c|c|c|c|c|c|c|c|}
\hline Component & $\begin{array}{l}\text { Length of } \\
\text { upstream flow } \\
\text { path }\end{array}$ & $\begin{array}{l}\text { Length of } \\
\text { downstream } \\
\text { flow path }\end{array}$ & Length of gap & $\begin{array}{l}\text { Rotor outer } \\
\text { diameter }\end{array}$ & $\begin{array}{l}\text { Stator outer } \\
\text { diameter }\end{array}$ & $\begin{array}{l}\text { Rotor thick- } \\
\text { ness }\end{array}$ & $\begin{array}{l}\text { Inner diameter } \\
\text { of the flow } \\
\text { path }\end{array}$ & $\begin{array}{l}\text { Outer diameter } \\
\text { of the flow path }\end{array}$ \\
\hline Size/mm & 299 & 381 & 2 & 76 & 80 & 5 & 80 & 88 \\
\hline
\end{tabular}


simulation results, and the system friction torque can be determined experimentally.

\section{Hydraulic torque acting on the rotary valve}

The hydraulic torque acting on the rotary valve under different flow rates changes with time as shown in Fig. 3. It can be seen from the figure that when the flow rate is constant, the hydraulic torque changes periodically, and the positive and negative amplitudes are basically the same. As the flow rate increases, the amplitude of the hydraulic torque increases greatly, but the curve phase is the same. For example, when the flow rate is $40 \mathrm{~L} / \mathrm{s}$, the amplitude of hydraulic torque is $2.5 \mathrm{~N} \cdot \mathrm{m}$ or more.

\section{System friction torque}

In this section, the friction torque acting on the rotating system is measured experimentally. The experimental device diagram is shown in Fig. 4. The test bench is mainly composed of a water tank, a mud pump, a flow meter, a servo motor, a torque sensor, an inlet pressure sensor, an angle encoder, an outlet pressure sensor, a throttle valve, a signal acquisition device and a computer. The torque sensor and the angle encoder are installed between the servo motor and the rotary valve and are, respectively, used for measuring the torque and the angle of rotation when the rotary valve rotates. In order to accurately measure the pressure at both ends of the rotary valve, an inlet pressure sensor and an outlet pressure sensor are, respectively, installed at the inlet and the outlet of the rotary valve. The flow meter is used to measure the flow through the rotary valve. The signal acquisition device is used to collect the data collected by each sensor and transmit the data to a computer for processing. The mud pump used in the experiment is a three-cylinder reciprocating pump, so it can be output at a steady flow rate. At the same time, a throttle

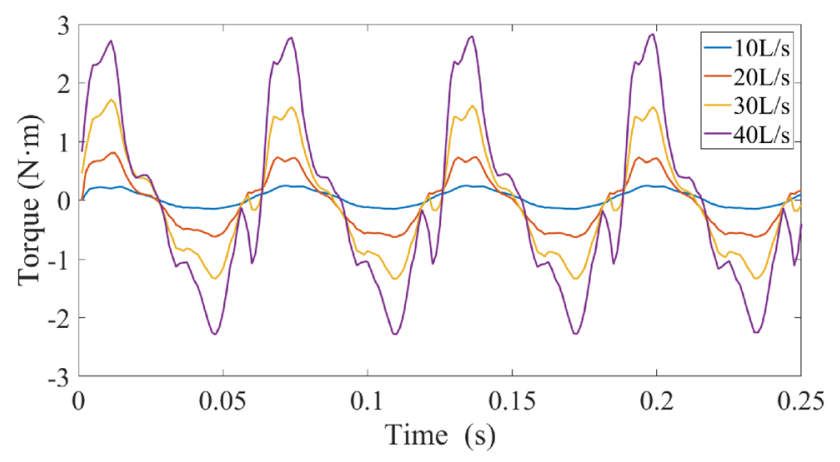

Fig. 3 Hydraulic torque acting on the rotary valve under different flow rates

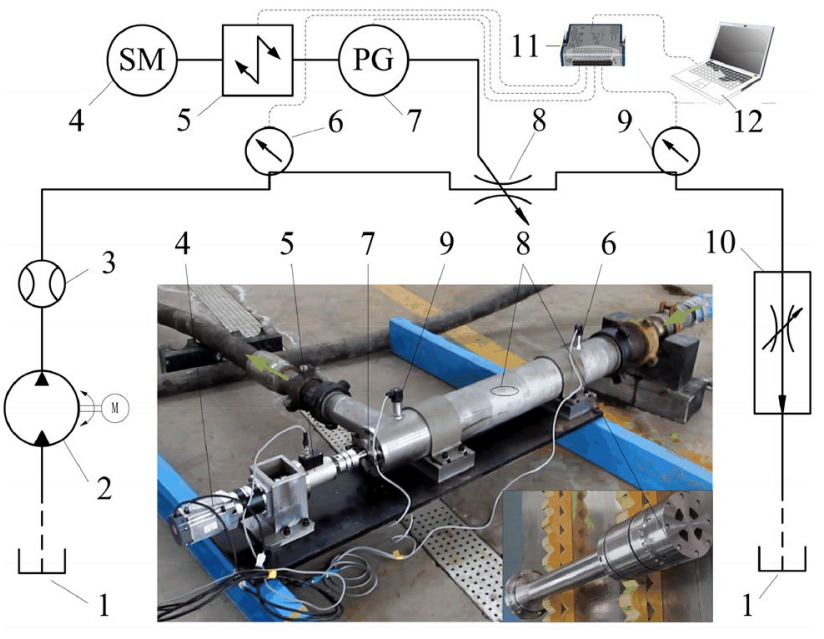

Fig. 4 System friction torque test device 1-water tank, 2-mud pump, 3-flow meter, 4-servo motor, 5-torque sensor, 6-inlet pressure sensor, 7-angle encoder, 8-turn valve, 9-outlet pressure sensor, 10- Throttle, 11-signal acquisition device, 12-computer

valve is installed at the outlet to ensure that no vacuum is present at the outlet when the rotary valve is fully closed.

In the experiment, the rotary valve was not installed, and the flow rate in the system was adjusted to $20 \mathrm{~L} / \mathrm{s}$ by adjusting the output of the pump. The servo motor is then adjusted to change the speed of the axis. The torque sensor could measure the system torque at different speeds. Because the system was in the no-load state, the system torque was the friction torque. The test data are shown in Table 2. It can be seen from the table that when the rotational speed is constant, the friction torque acting on the system gradually increases with increase in the drilling fluid pressure. At the same time, when the drilling fluid pressure is constant, the increase of the shaft speed will slightly reduce the system friction torque. Therefore, when the rotational speed of the shaft is $4 \mathrm{r} / \mathrm{s}$, the value of the system friction torque can be considered to be $2 \mathrm{~N} \cdot \mathrm{m}$.

Table 2 System friction torque measured at a drilling fluid flow rate of $20 \mathrm{~L} / \mathrm{s}$

\begin{tabular}{lllll}
\hline Torque/N m & \multicolumn{4}{l}{ Drilling fluid pressure } \\
\cline { 2 - 5 } & $0 \mathrm{MPa}$ & $1 \mathrm{MPa}$ & $1.5 \mathrm{MPa}$ & $2 \mathrm{MPa}$ \\
\hline Rotating speed & & & & \\
$7.5 \mathrm{r} / \mathrm{min}$ & 1.3 & 1.5 & 1.9 & 2 \\
$15 \mathrm{r} / \mathrm{min}$ & 1 & 1.3 & 1.6 & 1.8 \\
$30 \mathrm{r} / \mathrm{min}$ & 1 & 1 & 1.3 & 1.3 \\
\hline
\end{tabular}




\section{Analysis of load characteristics of DFCWG}

According to the characteristics of hydraulic torque acting on the rotary valve and system friction torque, the DC component obtained by the Fourier transform of the rotary valve hydraulic torque is numerically added to the system friction torque to obtain the value of the DC component of the load torque, as shown in Fig. 5. It can be seen from the figure that the DC component of the load torque decreases slightly with the increase of the flow rate, and the maximum difference is $0.2547 \mathrm{~N} \cdot \mathrm{m}$.

Due to the large proportion of high-frequency harmonics in the load torque, if the fundamental frequency signal is used as the alternating component of the load torque, the error is large. Therefore, the alternating component of the load torque is analyzed by the fitting method. The MATLAB fitting toolbox is used to obtain the alternating component of the load torque under different flow rates, as shown in Fig. 6. It can be seen from the figure that the alternating component of the load torque under different flow rates changes sinusoidally and reaches the extreme value at the same phase. As the flow rate increases, the amplitude of the load torque alternating component gradually becomes larger.

\section{The fluid-magnetic cooperative compensation method and compensation devices design}

\section{The fluid-magnetic cooperative compensation method}

As the drilling fluid flows through the turbine, the momentum of the fluid changes, producing a reaction torque on the turbine that provides a constant torque when the turbine speed is the same and the flow rate is constant. If the turbine is coaxially connected to the rotary valve with the

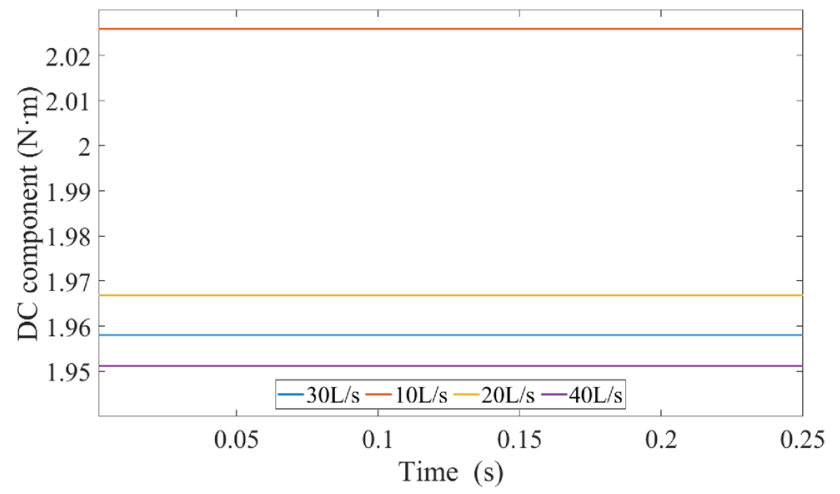

Fig. 5 DC component of load torque under different flow rates

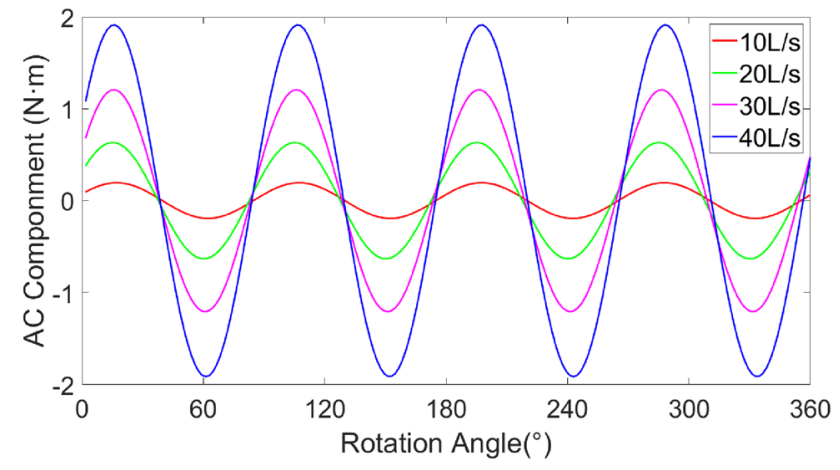

Fig. 6 Fitting curve of load torque alternating component under different flow rates

number of torque generated by the turbine being the same as the DC component of the load torque, and the direction is reversed, then the DC component of the load torque can be compensated. The magnetic coupler is alternately installed with the $\mathrm{N}$ and $\mathrm{S}$ magnetic poles of the fixed rotor to generate a magnetic torque that alternates with time, so that the magnetic coupling can be used to compensate for the alternating component. Therefore, the turbine and magnetic coupling structure can be connected in series with the rotary valve to compensate for the load torque.

A schematic diagram of the load compensation device for the continuous wave generator is shown in Fig. 7. The unit consists of a rotary valve, a turbine and a magnetic coupler. When the continuous wave generator is working, the motor rotates to drive the rotor across the shaft, and at the same time drives the turbine and the rotor of magnetic coupler connected to the shaft. When the flow rate of the drilling fluid is constant, a constant torque can be generated on the turbine, which can be used to compensate the DC component of the load torque, and the magnetic coupler can generate alternating torque to compensate the alternating component of the load torque.

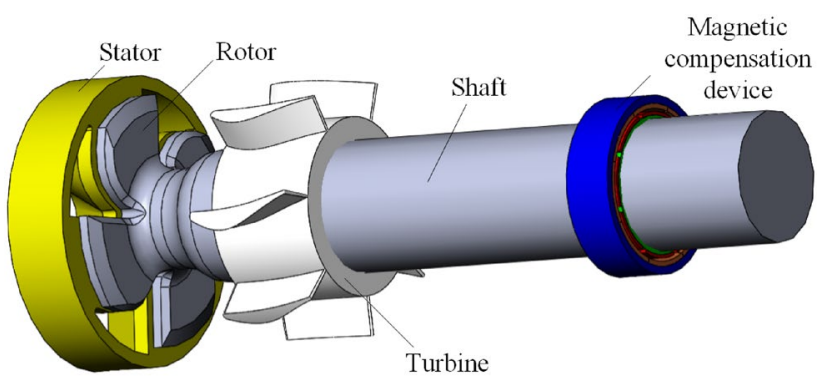

Fig. 7 Structure of load compensation device for low power continuous wave generator 


\section{Design of the load compensation device for DFCWG}

In order to get the best compensation effect, the overall layout design of the load compensation device is first required. In order to protect the magnetic device and also ensure its easy installation, the magnetic device is always placed behind the rotary valve and connected to the reducer. There are two ways to install the turbine. One way is to install the turbine behind the rotary valve. This method can ensure that the rotary valve produces high-quality pressure waves. In order to ensure the compensation effect of the turbine, the distance between the rotary valve and the turbine is set to $200 \mathrm{~mm}$ during the installation. The other way is to install the turbine in front of the rotary valve. This method can ensure the compensation effect of the turbine. In order to stabilize the flow field near the rotary valve, the distance between the turbine and the rotary valve is set to $200 \mathrm{~mm}$ during the installation.

\section{Compensation turbine structure design}

The structural design of the axial flow turbine is based on the DC component of the continuous wave generator load torque. The theoretical calculation formula of the one-flow design of the axial flow turbine can be expressed as follows (Hongbo 2012; Lei 2013; Lin 2014):

$M=\rho Q R\left(C_{1 u}-C_{2 u}\right)$

where $M$ is the turbine torque, $\rho$ is the drilling fluid density, $Q$ is the drilling fluid flow, $\mathrm{R}$ is the turbine equivalent radius, $C_{1 u}$ and $C_{1 u}$ are the absolute speeds of the inlet and outlet in the circumferential direction projection, respectively.

Based on this theory, the design of the compensation turbine is realized, and the design results are shown in Fig. 8 and Table 3.

\section{Structural design of compensation magnetic coupler}

Domestic and foreign scholars have done a lot of research on the design method of a magnetic coupler (Wei et al. 2017; Yu et al. 2013; Zina et al. 2017; Hongkui et al. 2017). The calculation methods of magnetic torque can be divided into two types: Gauss theorem solution method and empirical formula solving method. In the Gauss theorem solution method, the magnetic torque can be calculated by the following formula.

$T=\left(\frac{1}{5000}\right)^{2} \mathrm{KMHmSt}_{h} R_{c} \sin \left(\frac{m}{2} \phi\right)$

where $T$ is the torque that the magnetic drive can provide; $K$ is the magnetic circuit coefficient; $M$ is the magnetization,
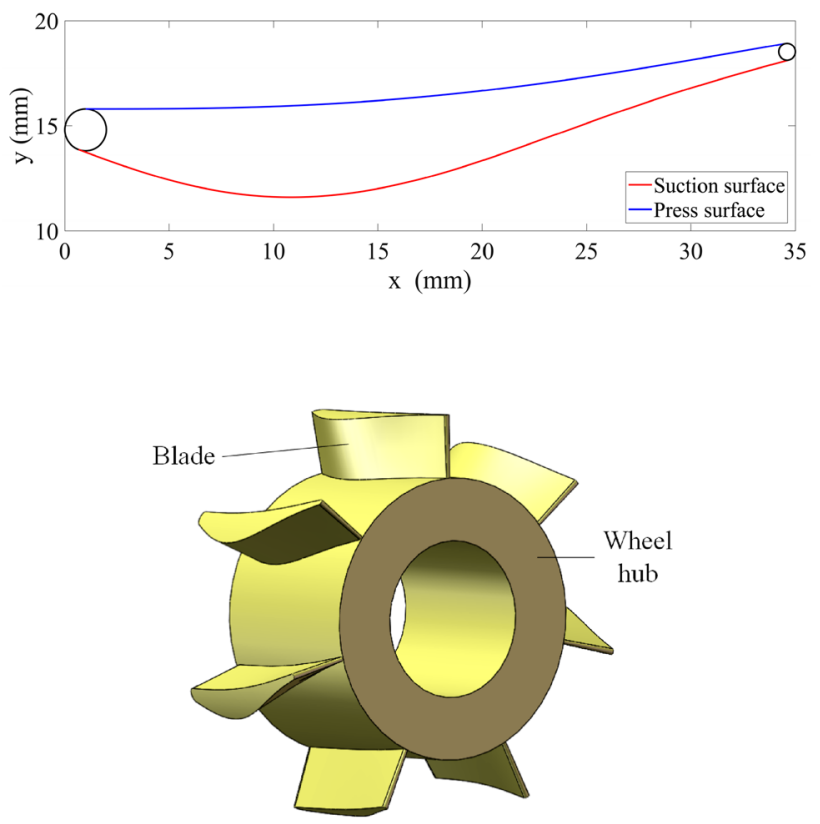

Fig. 8 Blade shape and 3D model of turbine

where $B_{m}$ and $H_{m}$ are the magnetic induction intensity and magnetic field intensity at the operating point; $H$ is the intensity of the magnetic field generated by the outer magnetic circuit at the inner magnet; $m$ is the number of poles of the magnetic pole; $S$ is the pole area of the magnetic pole; $t_{h}$ is the thickness of the magnet; $R_{c}$ is the average torque radius from the magnetic force acting on the inner magnetic pole to the center of movement; $\phi$ is the displacement angle at work.

The structure and principle of the compensating magnetic coupler are similar to that of the magnetic coupler, so we can refer to the design method of the magnetic coupler for the design of the compensating magnetic coupler. The Gauss theorem method is used in the design. The three-dimensional structure diagram is shown in Fig. 9. The device is composed of a shell, an outer magnet sleeve, an inner magnetic axis, a rotor sleeve, eight stator magnetic tiles and eight rotor magnetic tiles. There is an air gap between the rotor and the stator. When the rotor rotates, the stator exerts a magnetic force on the rotor to produce a magnetic torque. In the actual drilling process, the flow rate of drilling fluid will change, and from the above analysis, it can be found that the $\mathrm{AC}$ component of the load torque reaches the maximum value at the same phase at different flow rates. Therefore, the radial dimension of the compensating magnetic coupler applied under different flow rates remains unchanged, only the axial dimension is changed. The dimensions of the compensating magnetic coupler applied under different flow rates are shown in Tables 4 and 5. 
Table 3 Structure parameters of turbine

\begin{tabular}{llll}
\hline Parameters & Value & Parameters & Value \\
\hline Import absolute speed angle $\alpha_{1}$ & 86.2715 & Flow path height $B / \mathrm{mm}$ & 12 \\
Import relative speed angle $\beta_{1}$ & 90 & Import structure angle $\beta_{1 k}$ & 100 \\
Export absolute speed angle $\alpha_{2}$ & 96.9174 & Exit structure angle $\beta_{2 k}$ & 77.5116 \\
Relative speed angle of exit $\beta_{2}$ & 79.5116 & Inlet wedge angle $\varphi_{1}$ & 20 \\
Stator mounting angle $\alpha_{m}$ & 91.6083 & Exit wedge angle $\varphi_{2}$ & 5 \\
Height $s / \mathrm{mm}$ & 35 & Leading edge radius $r_{1} / \mathrm{mm}$ & 1 \\
Chord length $b / \mathrm{mm}$ & 35 & Trailing edge radius $r_{2} / \mathrm{mm}$ & 0.4 \\
Circumferential density $\bar{t} / \mathrm{mm}$ & 29.8 & Hub inner diameter $/ \mathrm{mm}$ & 30 \\
Leaf pitch $t / \mathrm{mm}$ & 29.6 & Wheel thickness $/ \mathrm{mm}$ & 12 \\
Number of blades $n$ & 7 & Turbine outer diameter $/ \mathrm{mm}$ & 78 \\
\hline
\end{tabular}

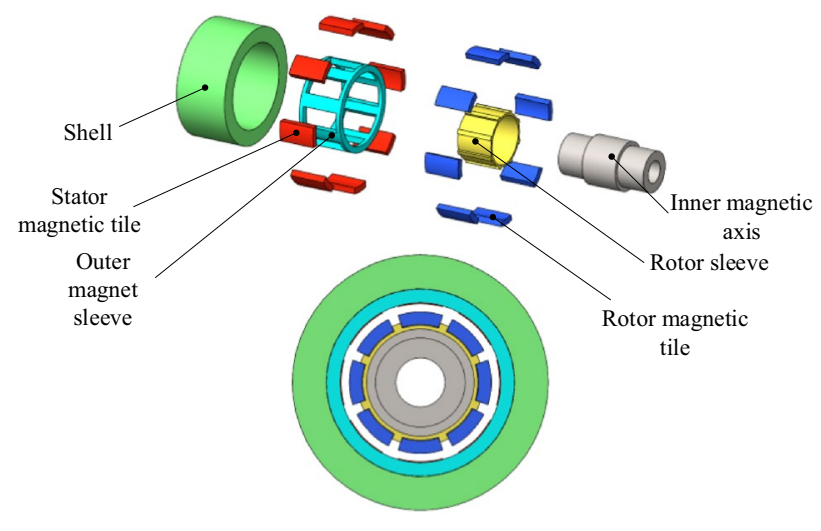

Fig. 9 Magnetic coupler

Table 4 Radial dimension of the magnetic compensation device

\begin{tabular}{llllll}
\hline Location & Wheel hub & Rotor yoke & Rotor & Stator & Stator yoke \\
\hline $\begin{array}{l}\text { Inner diameter/ } \\
\text { mm }\end{array}$ & 0 & 38 & 42 & 44 & 46 \\
$\begin{array}{l}\text { Outer diameter/ } \\
\text { mm }\end{array}$ & 38 & 42 & 44 & 49 & 54 \\
\hline
\end{tabular}

\section{Simulation and Analysis of compensation effect of Load Compensation Device}

\section{The hydraulic characteristics of the turbine}

Since the flow of fluid inside the turbine satisfies the ternary fluid control equation, CFD is required for simulation calculation (Yongbo et al. 2013). Meshing is performed using the mesh module in ANSYS/CFX software. As shown in Fig. 10, a tetrahedral mesh and a triangular prism mesh are used in the flow field at the turbine. The density of the drilling fluid was set to $997 \mathrm{~kg} / \mathrm{m}^{3}$, and the dynamic viscosity was set to $8.9 \times 10^{-4} \mathrm{~Pa} \cdot \mathrm{s}$. The theoretical model adopts the $k-\varepsilon$ model. The inlet type

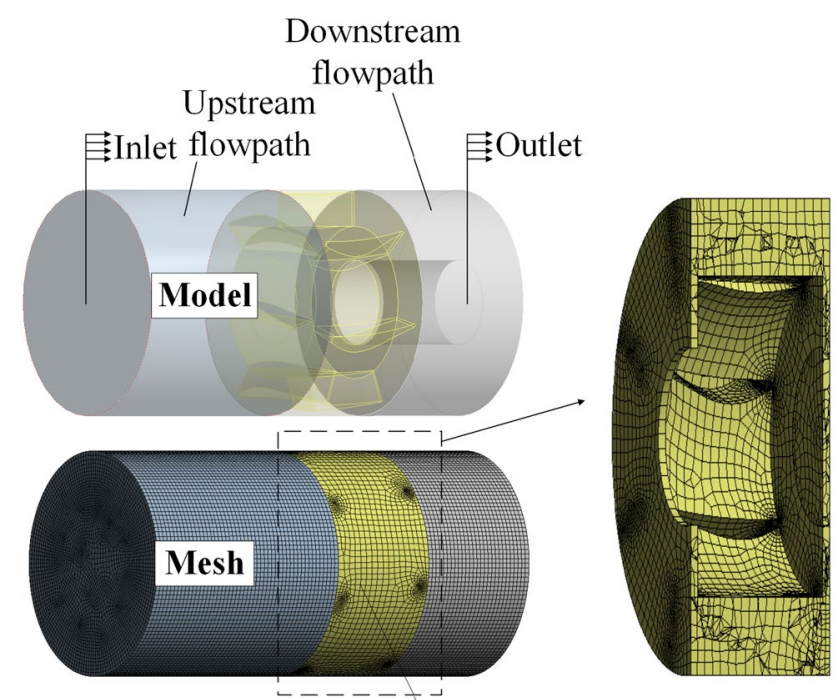

Tubine

Fig. 10 Grid settings and boundary conditions for turbine regions

should be set to the velocity inlet with the flow rate of $5.968 \mathrm{~m} / \mathrm{s}$ (corresponding to the flow rate of $30 \mathrm{~L} / \mathrm{s}$ ) and the outlet type is set to the constant pressure outlet with the relative pressure of $1.6 \mathrm{MPa}$. The flow field at the turbine is set to the rotating domain with a speed of $4 \mathrm{r} / \mathrm{s}$. All wall boundaries are assumed to have no slip boundaries and standard wall equations are used in the near wall region. The second-order backward Euler format is used to solve the model. The scaling residuals of all parameters and the absolute standard of convergence are set to $10^{-4}$.

The hydraulic torque acting on the turbine is shown in Fig. 11. It can be seen from the figure that when the inlet flow rate of the drilling fluid is $30 \mathrm{~L} / \mathrm{s}$, the hydraulic torque fluctuates due to the instability of the flow field in the initial stage. When the flow field is stabilized, the hydraulic torque is stable at $2.2 \mathrm{~N} \cdot \mathrm{m}$ with a design error of $6.4 \%$, so the turbine meets the design requirements. 


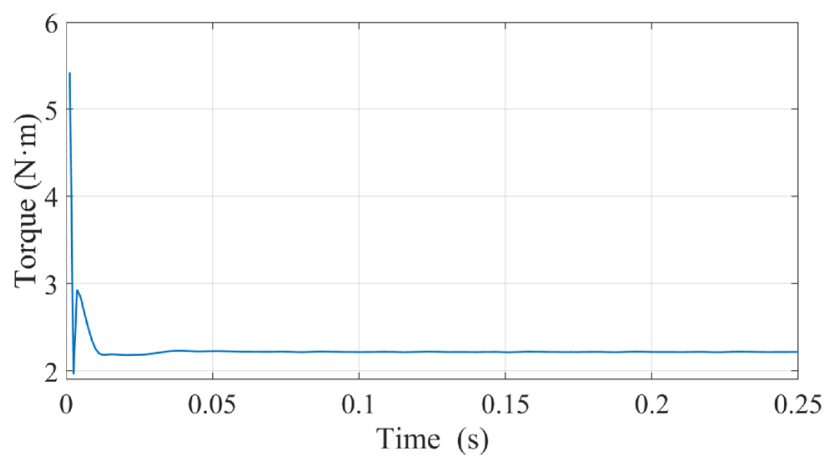

Fig. 11 Hydraulic torque acting on the turbine

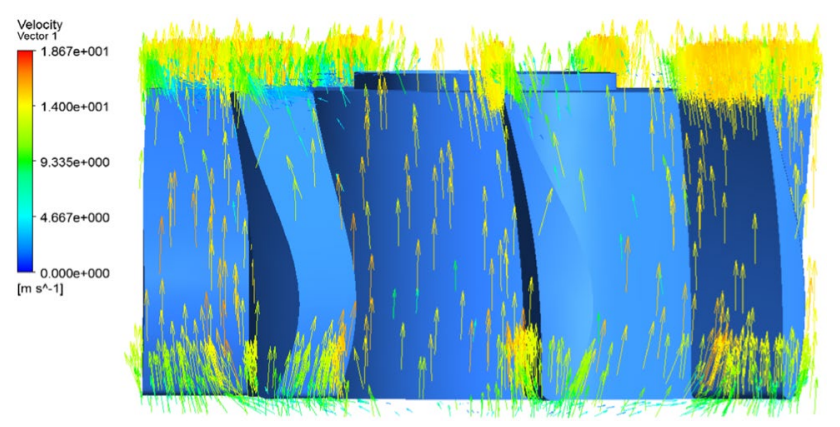

Fig. 12 Velocity field in the turbine area

The flow field inside the turbine is shown in Fig. 12. It can be seen from the figure that after the fluid enters the turbine, the fluid flowing along the blade enters the turbine with a flow rate of $14 \mathrm{~m} / \mathrm{s}$. The flow rate at the turbine outlet does not change substantially, but the direction changes significantly. The kinetic energy of the fluid at the inlet and outlet of the turbine does not change, but the momentum changes. For the fluid flowing along the flow channel, the flow rate at the turbine inlet is $14 \mathrm{~m} / \mathrm{s}$, and the velocity is almost unchanged when flowing out of the turbine, and the kinetic energy and momentum of this part of the fluid remain constant.

\section{Simulation of torque produced by the magnetic compensation device}

The designed magnetic coupling mechanism model is imported into ANSYS/Maxwell and the rotation domain and the solution domain are added. The rotation domain and the solution domain material are vacuum. The yoke material is iron. Since the magnetic coupling mechanism works underground for a long time, the magnetic pole should be made of a high-temperature resistant material. The samarium cobalt material (An Shizhong et al. 2014; Jing et al., 2017) is used in this section. The performance parameters of each material are shown in Table 6. In order to ensure the accuracy of the
Table 5 Axial dimension of magnetic compensation device under different working conditions

\begin{tabular}{llllll}
\hline Flow/(L/s) & 10 & 20 & 30 & 40 & 46 \\
\hline Axial dimension/mm & 5 & 7.5 & 15 & 30 & 54 \\
\hline
\end{tabular}

Table 6 Properties of material in various parts of the magnetic compensation device

\begin{tabular}{llcll}
\hline Material & $\begin{array}{l}\text { Volume } \\
\text { conductivity/ } \\
(\text { siemens/m) }\end{array}$ & $\begin{array}{l}\text { Mass } \\
\text { density/ } \\
\left(\mathrm{kg} / \mathrm{m}^{3}\right)\end{array}$ & $\begin{array}{l}\text { Coercivity } H_{c} / \\
(\mathrm{A} / \mathrm{m})\end{array}$ & $\begin{array}{l}\text { Rema- } \\
\text { nence } \\
B_{r} / \mathrm{T}\end{array}$ \\
\hline Vacuum & 0 & 0 & 0 & 0 \\
Steel_1008 & $2,000,000$ & 7872 & 0 & 0 \\
SmCo24 & $1,111,111$ & 8300 & $-756,000$ & 1.01 \\
\hline
\end{tabular}

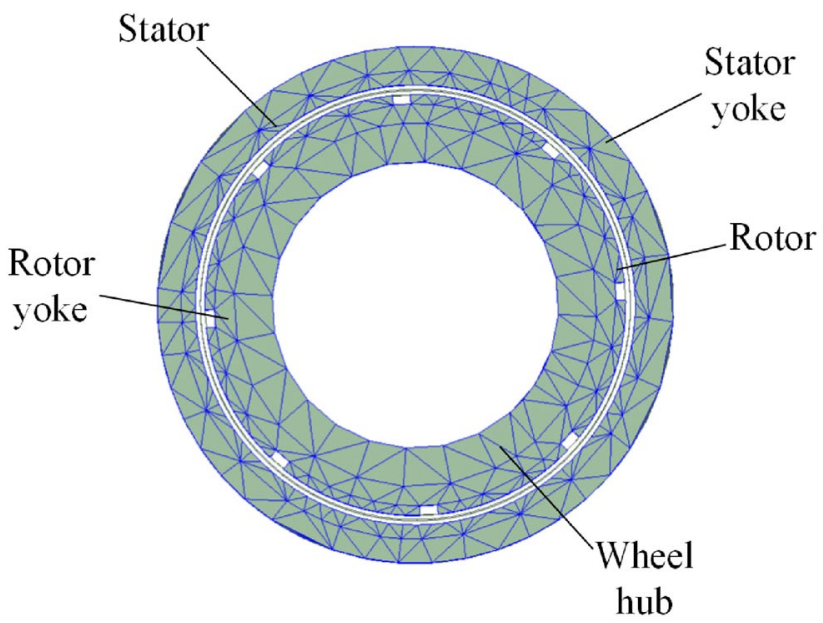

Fig. 13 Grid model of magnetic compensation device

calculation, mesh encryption is performed in the rotor and stator regions. The mesh model is shown in Fig. 13. Finally, the Maxwell equations are solved by an iterative method to solve the electromagnetic problem (Xing et al. 2011).

The magnetic torque is shown in Fig. 14. The magnetic device is used in the flow rate of $30 \mathrm{~L} / \mathrm{s}$. It can be seen from the figure that the amplitude of the magnetic torque curve and the alternative component of the load toque is approximate, and the direction is opposite; thus, the design of the magnetic compensation device meets the design requirement.

The magnetic induction distribution of the magnetic compensation device is shown in Fig. 15. It can be seen from the figure that the magnetic induction strength of the edge of the stator yoke is large with a maximum of $1.08 \mathrm{~T}$ and the magnetic induction intensity gradually decreases from the outside to the inside and reaches the minimum value in the air gap portion, which is $0.108 \mathrm{~T}$. Inside the magnetic 


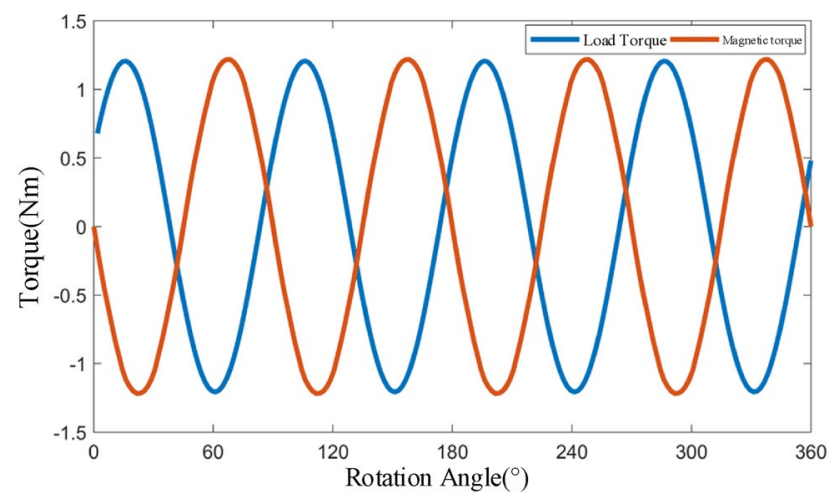

Fig. 14 Magnetic torque produced by magnetic compensation device

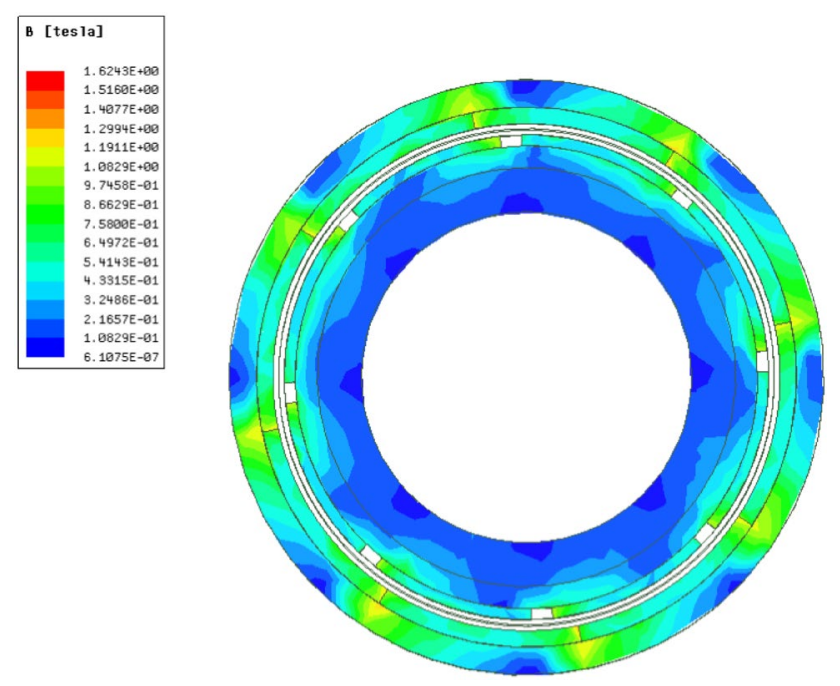

Fig. 15 Magnetic induction distribution of magnetic coupling mechanism

pole, the magnetic density distribution is uniform, but the magnetic density is large in the air gap portion, and there is almost no magnetic field in the hub region. It can be seen that the magnetic coupling mechanism has better magnetic properties.

\section{Analysis of compensation effect of load compensation device}

Since the magnetic coupling mechanism has no influence on the flow field, and the flow field between the turbine and the rotary valve has a coupling phenomenon, the flow field of the turbine and the rotary valve region can be simulated first in the simulation, and finally, the magnetic torque and the hydraulic torque are performed to evaluate the compensation effect of the load compensation device. First, ANSYS/CFX is used to analyze the total hydraulic torque after the coupling of the rotary valve and the

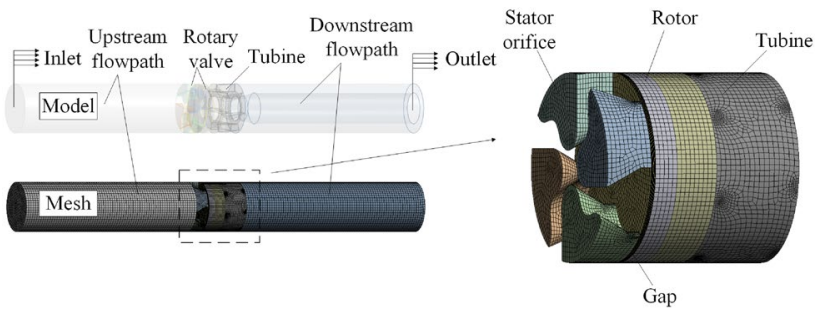

Fig. 16 Grid model and boundary conditions when the turbine is mounted behind the rotary valve



Fig. 17 System load torque at flow rate of $30 \mathrm{~L} / \mathrm{s}$

turbine, and the turbine and rotary valve regions are set to the rotating domain. The rest of the settings are the same as those for analyzing the hydraulic torque acting on the rotary valve.

\section{The turbine is mounted behind the rotary valve}

The flow field model of the turbine mounted behind the rotary valve is shown in Fig. 16. The system load torque at a flow rate of $30 \mathrm{~L} / \mathrm{s}$ is shown in Fig. 17. It can be seen from the figure that the maximum load torque after compensation is $6.9 \mathrm{~N} \cdot \mathrm{m}$, and the maximum load torque before compensation is $3.7 \mathrm{~N} \cdot \mathrm{m}$. The amplitude of the compensated load torque curve becomes larger compared to the pre-compensation amplitude. At the same time, the compensated load torque reaches the maximum value when the rotary valve angle is $64.8^{\circ}$, and the load torque before compensation reaches the maximum value when the rotary valve angle is $16.2^{\circ}$, which is due to the rotation of the rotary valve which makes the direction of the fluid change in the inlet of turbine. As can be seen from Fig. 17, the turbine can be used to compensate for the DC component of the load torque, but the distance from the rotary valve is too close which causes interference between the two fields. 


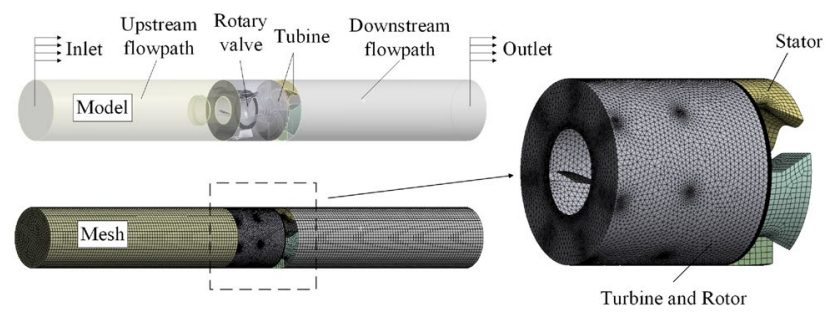

Fig. 18 Grid model and boundary conditions when the turbine is installed in front of the rotary valve

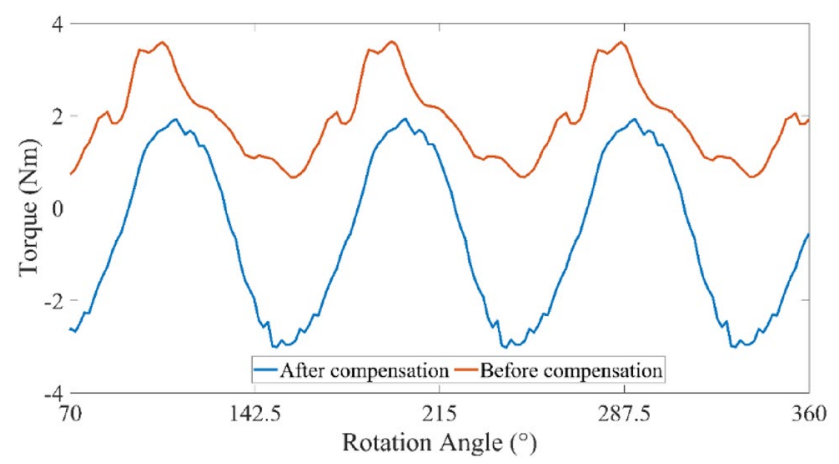

Fig. 19 System load torque curve when the turbine is placed in front of the rotary valve at a flow rate of $30 \mathrm{~L} / \mathrm{s}$

\section{The turbine is mounted in front of the rotary valve}

The flow field model when the turbine is installed in front of the rotary valve is shown in Fig. 18. The system load torque when the turbine is installed in front of the rotary valve at a flow rate of $30 \mathrm{~L} / \mathrm{s}$ is shown in Fig. 19. It can be seen from the figure that the DC component of the compensated load torque is $0.6 \mathrm{~N} \cdot \mathrm{m}$, which is $73.08 \%$ less than that before the compensation. At the same time, the load torque curve before and after compensation reaches the maximum value at the same turning valve angle. The amplitude of the compensated load torque is larger than that before the compensation and the amplitude increases from $3 \mathrm{~N} \cdot \mathrm{m}$ before compensation to $5 \mathrm{~N} \cdot \mathrm{m}$ after compensation. This is due to the presence of the turbine which increases the energy of the fluid passing through the turbine region.

The hydraulic torque acting on the turbine when the turbine is installed in front of the rotary valve at a flow rate of $30 \mathrm{~L} / \mathrm{s}$ is shown in Fig. 20. It can be seen from the figure that in the integrated system of the turbine and the rotary valve, the rotating rotary valve interferes with the turbine flow field, causing slight disturbance in the hydraulic torque of the turbine, resulting in a small fluctuation of about $3.25 \mathrm{~N} \cdot \mathrm{m}$ in the turbine torque. However, the amplitude of the fluctuation is small and thus can better compensate the DC component of the system load torque.

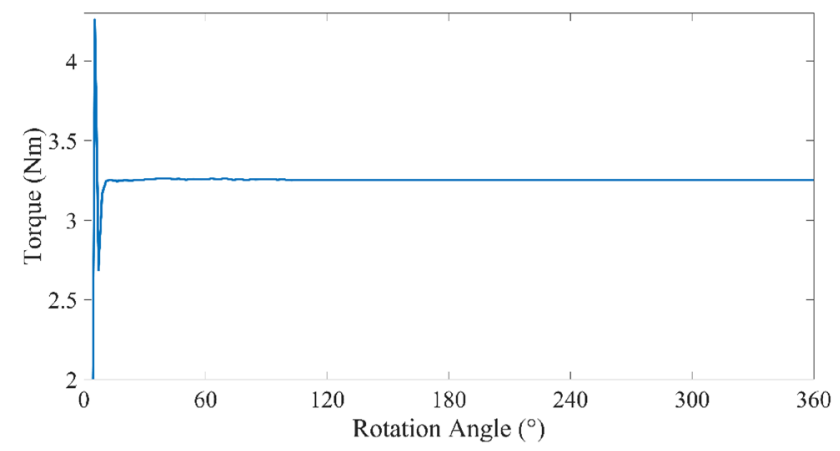

Fig. 20 Torque produced by turbine when the turbine is placed in front of the rotary valve at a flow rate of $30 \mathrm{~L} / \mathrm{s}$

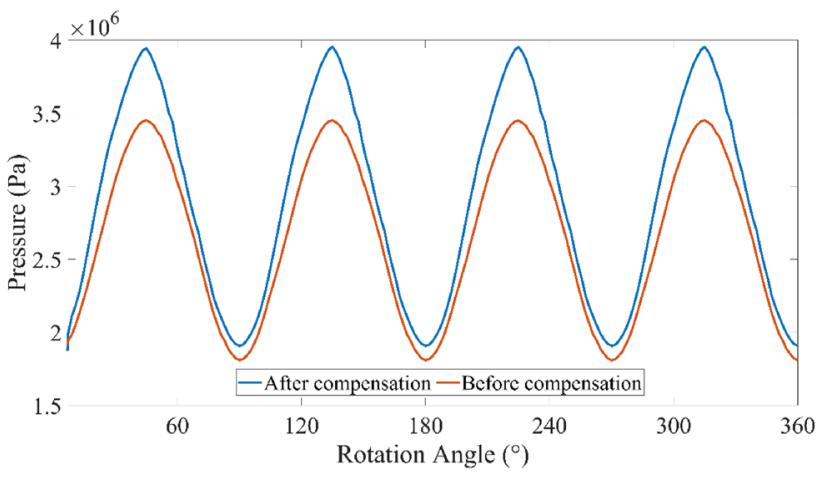

Fig. 21 Pressure wave signal when the turbine is placed in front of the rotary valve at a flow rate of $30 \mathrm{~L} / \mathrm{s}$

The pressure wave signal is shown in Fig. 21 when the turbine is placed at a flow rate of $30 \mathrm{~L} / \mathrm{s}$ in front of the rotary valve. Compared with the original pressure wave signal, the addition of the turbo compensation device causes the maximum value of the pressure wave signal to increase significantly and the resolution of the signal to improve significantly. The phase of the signal does not change significantly. After adding the turbine, the pressure wave has a maximum value of $4 \mathrm{MPa}$ and a minimum value of $1.9 \mathrm{MPa}$.

The system load torque after adding the turbine and the magnetic compensation device is shown in Fig. 22. It can be seen from the figure that after compensation, the peak of the load torque is changed from 3.7 to $0.55 \mathrm{~N} \cdot \mathrm{m}$, and the trough value is changed from $0.7 \mathrm{~N} \cdot \mathrm{m}$ to $-1 \mathrm{~N} \cdot \mathrm{m}$, which greatly reduces the load torque of the system. However, there is still a small oscillation of the compensated load torque. Considering the complicated condition of the underground work, the designed magnetic torque needs to be slightly larger than the amplitude of the actual load torque AC component. From the analysis results, the compensation device can effectively compensate the load torque and can also verify the feasibility of the fluid-magnetic cooperative compensation method. 


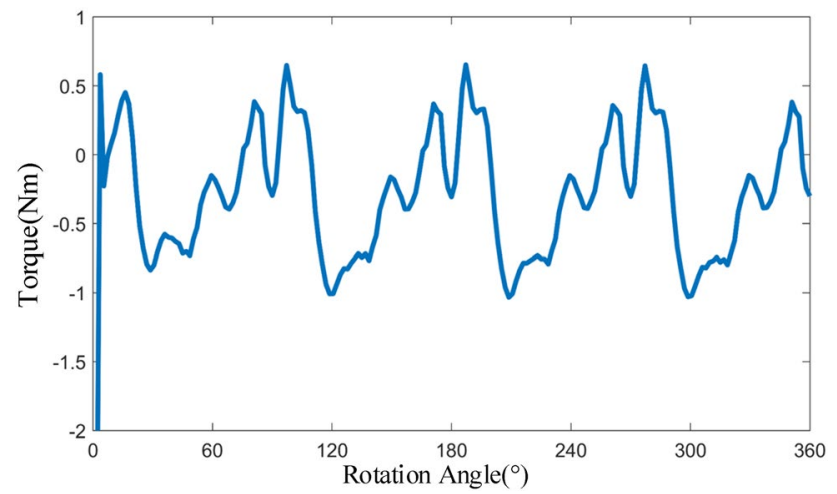

Fig. 22 Comprehensive compensation effect

In the drilling process, the displacement of drilling fluid needs to be changed at different depths. The hydraulic torque generated by the load compensation turbine can be automatically adjusted according to the displacement of drilling fluid to compensate the DC component of the load torque. For the alternating component, the axial length of the magnetic compensation device can be adjusted to produce the corresponding magnetic torque for compensation. The system can ensure the load compensation effect and improve the control accuracy according to the rapid change in accord with drilling fluid displacement in the actual drilling process. This system can reduce the load torque to ensure the control effect of DFCWG, and then affect the continuous wave signal quality. Therefore, this system only plays an auxiliary role in DFCWG and cannot directly affect the continuous wave signal waveform.

\section{Conclusion}

In this paper, the load torque characteristics of DFCWG are analyzed, and the fluid-magnetic cooperative compensation method is proposed. That is, the turbine compensates the DC component of the load torque, and the magnetic coupling mechanism compensates for the alternating component of the load torque. The compensation effect of the load compensation device is analyzed, and the rationality of the proposed compensation method and compensation device is verified. The following conclusions are drawn:

(1) The hydraulic torque of the rotary valve changes periodically and the maximum value increases with the increase in the flow rate. The system friction torque is constant at $2 \mathrm{~N} \cdot \mathrm{m}$, and the load torque of the motor output is in the range of -0.3 to $4.7 \mathrm{~N} \cdot \mathrm{m}$.

(2) The compensation turbine cannot effectively compensate the load torque when it is installed behind the rotary valve. When installed in front of the rotary valve, it can compensate $73.08 \%$ of the load torque DC component.

(3) The magnetic coupling needs to be installed with the reducer, and after the magnetic coupling is added, the maximum value of the load torque is changed from $3.7 \mathrm{~N} \cdot \mathrm{m}$ to $0.55 \mathrm{~N} \cdot \mathrm{m}$, and the load compensation device can effectively compensate the load torque.

(4) After adding the compensation device, the load torque can be reduced and the control difficulty is diminished, which benefit for the improvement in the similarity between actual and ideal continuous wave waveform.

(5) In our future work, the control system will be designed and the system performance will be verified.

Acknowledgement We would like to thank the anonymous reviewers for their valuable suggestions and corrections.

Funding This research was supported by the Fundamental Research Funds for the Central University (Grant No. 19CX02066A), in part by the Key Research and Development Program of Shandong Province (Grant 2019GHZ001) and in the part by the China University of Petroleum (East China) 2020 Graduate Innovation Project (Grant No. YCX2020033).

Open Access This article is licensed under a Creative Commons Attribution 4.0 International License, which permits use, sharing, adaptation, distribution and reproduction in any medium or format, as long as you give appropriate credit to the original author(s) and the source, provide a link to the Creative Commons licence, and indicate if changes were made. The images or other third party material in this article are included in the article's Creative Commons licence, unless indicated otherwise in a credit line to the material. If material is not included in the article's Creative Commons licence and your intended use is not permitted by statutory regulation or exceeds the permitted use, you will need to obtain permission directly from the copyright holder. To view a copy of this licence, visit http://creativecommons.org/licenses/by/4.0/.

\section{References}

Hahn D, Peters V, Rouatbi C, Eggers H (2005) Oscillating shear valve for mud pulse telemetry and associated methods of use. United States Patent: US 6975244 B2

Hongbo Z (2012) Turbine blade design and hydraulic performance simulation optimization of Turbine drill. China University of Geosciences

Hongkui C, Bingfu Z, Liping Z (2017) Research on torque characteristics of permanent magnet magnetic coupler based on ansoft. Coal Technology 36(03):288-291

Jia P (2010) Experimental study on design and signal transmission characteristics of drilling fluid continuous wave generator. China University of Petroleum

Jia P, Fang J, Su Y et al (2010) Analysis on rotary valve hydraulic torque of drilling fluid continuous wave signal generator. J China Univ Petrol (Edition Nat Sci) 1:23

Jing Hu, Liang W, Tianping Z, Jingdong W (2017) Application of samarium cobalt permanent magnet material in $30 \mathrm{~cm}$ Helium ion thruster. Magn Mater Devices 9(25):21-25 
Klotz C, Wassermann I, Hahn D (2008) Highly flexible mud-pulse telemetry: a new system. SPE Indian oil and gas technical conference and exhibition. Society of Petroleum Engineers.

Lavrut E, Kante A, Rellinger P, Gomez SR (2005) Inventors; Schlumberger Technology Corp, assignee. Pressure pulse generator for downhole tool. United States patent US 6970398

Lei J (2013) Blade Design and CFD Analysis of Turbine Drills. Mongolia Industrial University

Lin G (2014) Development and technical improvement of turbine mud generator for MWD. China Petroleum and Chemical Standards and Quality

Namuq MA, Reich M, Bernstein S (2013) Continuous wavelet transformation: A novel approach for better detection of mud pulses. $\mathrm{J}$ Petrol Sci Eng 110:232-242

Rong S (2011) Split type rotary valve for continuous wave pressure pulse generator. China Patent: CN 201826833 U, 5.11.

Shiqin D (2012) Analytical calculation of torque of radial magnetizing magnetic coupler in magnetic pump 15(4):216-220

Shizhong A, Tianli Z, Chengbao J (2014) High Performance Antioxidant SmCo High Temperature Permanent Magnetic Materials. Acta Aeronaut Sinica 35(10):2794-2801

Wei L, Bin Z, De Z (2017) Magnetic drive and its application and design. Mech Design Manuf 5(5):148-150

Wu J, Zhang R, Wang R (2017) Mathematical model and optimum design approach of sinusoidal pressure wave generator for downhole drilling tool. Appl Math Model 47:587-599
Wu J, Zhou B, Qin D et al (2020) Mathematical model and analysis of characteristics of downhole continuous pressure wave signal. J Petrol Sci Eng 186:106706

Xing D, Shunqi M, Zhiwei W, Wei L (2011) Analysis of coupled magnetic field of magnetic rotor of cylindrical magnetic drive mechanism. Light Ind Mach 29(6):56-58

Yan Z, Geng Y, Wei C, Wang T, Gao T, Shao J et al (2018) Design of a continuous wave mud pulse generator for data transmission by fluid pressure fluctuation. Flow Meas Instrum 59:28-36

Yongbo Bu, Jin F, Yun Z, Jun Y (2013) Design and experimental study of a wing-type blade impact turbine. Mach Res Appl 1:29-33

Yu Z (2013) Design of Magnetic Coupling and Study on Eddy Current Loss. Zhejiang University

Zhan L (2012) research on control method of rotary valve of downhole mwd drilling fluid pressure wave generator. China University of Petroleum

Zina Z, Wei M (2017) Analysis of three-dimensional transmission torque and characteristic parameters of magnetic coupling coupling. Electric Mach Control Sci 21(10):94-101

Publisher's note Springer Nature remains neutral with regard to jurisdictional claims in published maps and institutional affiliations. 